\title{
Contribuições da disciplina Teorias e Práticas do Ensino e Aprendizagem no processo de formação de mestrandos da Educação Profissional e Tecnológica: aprendizagens múltiplas em cenários de pandemia
}

\section{Contributions of the subject Theories and Practices of Teaching and Learning in the process of training masters students in Professional and Technological Education: multiple learning in pandemic scenarios}

\section{Aportes de la asignatura Teorías y Prácticas de Enseñanza y Aprendizaje en el proceso de formación de estudiantes del Máster en Educación Profesional y Tecnológica: aprendizaje múltiple en escenarios de pandemia}

\author{
Xavier, Cristine Roberta Piassetta ${ }^{1}$ (Curitiba, PR, Brasil) \\ ORCID ID: http://orcid.org/0000-0003-2544-0881 \\ Machado, Mércia Freire Rocha Cordeiro² (Curitiba, PR, Brasil) \\ ORCID ID: http://orcid.org/0000-0001-9401-1453
}

\begin{abstract}
Resumo
Este artigo busca analisar as percepções dos estudantes do Mestrado Profissional em Educação Profissional e Tecnológica (ProfEPT) quanto às contribuições da disciplina Teorias e Práticas do Ensino e Aprendizagem (TPEA) como espaço de Formação. Caracteriza-se como de abordagem qualitativa, do tipo exploratória. A coleta dos dados ocorreu por intermédio da revisão da literatura e a aplicação de questionários a 23 mestrandos. A análise dos questionários foi realizada por meio da análise de conteúdo, na perspectiva de Bardin (2011). Os procedimentos de organização dos questionários possibilitaram a identificação de duas categorias iniciais referentes as contribuições da TPEA como espaço de Formação para a EPT: i) na proposta das Atividades Pedagógicas Não Presenciais (APNPs) e ii) na aprendizagem do mestrando. A experiência nos mostrou que a proposta pedagógica teve destaque em quatro princípios básicos: i) da autonomia; ii) da pesquisa; iii) da interação; e iv) da colaboração. Mediante esses princípios, promoveu-se nos mestrandos múltiplas aprendizagens: i) aprofundamento teórico; ii) a construção coletiva; iii) a reflexão crítica; e iv) a autoria e a coautoria nos envolvidos no processo. Com o processo analítico, concluímos que é necessário pluralizar e individualizar a ação mediacional, recorrendo a princípios e estratégias intervencionais, que podem ser relevantes na aprendizagem.
\end{abstract}

Palavras-chave: Teoria e Prática do Ensino e Aprendizagem. Mestrado Profissional. Educação Profissional e Tecnológica. Espaço de Formação. ProfEPT.

\begin{abstract}
This article seeks to analyze the perceptions of the students of the Professional Master in Professional and Technological Education (ProfEPT) regarding the contributions of the discipline Theories and Practices of Teaching and Learning (TPEA) as a training space. It is characterized as a qualitative, exploratory approach. Data collection occurred through a literature review and questionnaires in 23 strata. An analysis of the questionnaires was carried out through content analysis, from the perspective of Bardin (2011). The procedures for organizing the questionnaires made it possible to identify two initial categories referring to the contributions of TPEA as a training space for EFA: i) in the proposal for NonPresential Pedagogical Activities (APNPs) and ii) in the student's learning. Experience has shown us
\end{abstract}

\footnotetext{
1 Professora do Ensino de Arte do Instituto Federal do Paraná (IFPR), campus Curitiba. Professora permanente do Programa de Pós-Graduação em Educação Profissional e Tecnológica (ProfPET). cristine.xavier@ifpr.edu.br 2 Professora do Instituto Federal do Paraná e pesquisadora da Pontifícia Universidade Católica do Paraná. mercia.machado@ifpr.edu.br 
that the pedagogical proposal was highlighted in four basic principles: i) autonomy; ii) research; iii) interaction; and iv) collaboration. Through these principles, multiple apprenticeships were promoted in the master's students: i) theoretical deepening; ii) collective construction; iii) critical reflection; and iv) authorship and co-authorship in those involved in the process. With the analytical process, we conclude that it is necessary to pluralize and individualize mediation action, using interventional principles and strategies, which can be relevant in learning.

Keywords: Theory and Practice of Teaching and Learning. Professional Master's. Professional and Technological Education. Training Space. ProfEPT.

\section{Resumen}

Este artículo busca analizar las percepciones de los estudiantes del Máster Profesional en Educación Profesional y Tecnológica (ProfEPT) con respecto a las contribuciones de la disciplina Teorías y Prácticas de Enseñanza y Aprendizaje (TPEA) como un espacio de formación. Se caracteriza por un enfoque cualitativo, del tipo exploratorio. La recolección de datos se realizó a través de la revisión de la literatura y la aplicación de cuestionarios a 23 estudiantes del Máster. El análisis de los cuestionarios se realizó a través del análisis de contenido, desde la perspectiva de Bardin (2011). Los procedimientos de organización de los cuestionarios permitieron identificar dos categorías iniciales que se refieren a las contribuciones de la TPEA como un espacio de formación para la EPT: i) en la propuesta de las Actividades Pedagógicas No Presenciales (APNP) y ii) en el aprendizaje del estudiante del Máster. La experiencia nos ha demostrado que la propuesta pedagógica se destacó en cuatro principios básicos: i) autonomía; ii) investigación; iii) interacción; y iv) colaboración. A través de estos principios, se promovieron múltiples aprendizajes en los estudiantes del Máster: i) profundización teórica; ii) construcción colectiva; iii) reflexión crítica; y iv) autoría y coautoría en los involucrados en el proceso. Con el proceso analítico, concluimos que es necesario pluralizar e individualizar la acción de mediación, utilizando principios y estrategias de intervención, que pueden ser relevantes en el aprendizaje.

Palavras-Clave: Teoría y práctica de la enseñanza y el aprendizaje. Máster profesional. Educación profesional y tecnológica. Espacio de entrenamiento. ProfEPT.

\section{Introdução}

Mais de 1,5 bilhão de alunos e 60,3 milhões de professores de 165 países foram afetados pelo fechamento de escolas devido à pandemia do coronavírus. Fomos pegos de surpresa e tivemos que nos adequar a uma nova realidade de vida em maior ou menor grau. Nessa crise de proporção global, educadores e famílias tiveram que lidar com a imprevisibilidade e (re)aprender a ensinar de novas formas. Esta pandemia desvelou o modelo tradicional de ensino e as escolas estão sendo compelidas a criarem estratégias para que a aprendizagem continue acontecendo, mesmo que de forma remota.

Ao ultrapassarmos as paredes da sala de aula, descobrimos um mundo de oportunidades. Tivemos que aportar recursos e conhecimentos especializados em tecnologia, conectividade, inovação e criatividade a favor da continuidade da educação. Os professores tiveram que experimentar novas formas de ensinar, novas 
ferramentas de avaliação e, os estudantes, que organizar e planejar o seu aprendizado no mundo digital, ou seja, experimentaram novas formas de aprender. $E$ com isso, a educação nunca mais voltará a ser a mesma que antes.

$\mathrm{O}$ isolamento social está criando novos hábitos, comportamentos e processos - tanto nas famílias, quanto nas instituições de ensino - no que se refere às suas estruturas e metodologias. Tivemos que aprender a lidar com a imprevisibilidade e isso exigiu um trabalho em grupo muito mais comprometido, alinhado e cooperativo que, mesmo distantes, podemos unir esforços em prol de um objetivo maior.

Estamos vivendo um "novo normal" e neste contexto as instituições de ensino (IEs) estão em processo de adaptação. Algumas IEs optaram por aguardar a pandemia passar para reabrir as atividades. Outras, diante das incertezas, estão trabalhando na contingência e buscando fazer o possível por meio das aulas remotas, de ambientes virtuais, do envolvimento com a comunidade, etc. Umas estão no processo de busca no investimento em tecnologia, formação de professores e novos materiais, objetivando oferecer uma educação remota com uma estruturada mínima. Outras decidiram suspender suas atividades para a preparação de um possível retorno e, com isso, estão no processo de reflexão sobre que competências os professores necessitavam para organizar cursos para os seus professores, quais plataformas educacionais serão utilizadas, múltiplas mídias e materiais para que atendam suas necessidades pontuais, com o foco na inclusão de todos os seus alunos.

Passado algum tempo do período de isolamento social, suspensão das atividades escolares, as instituições de ensino - em nível municipal, estadual, federal e a rede privada, entendendo sua responsabilidade social, estão se posicionando com o intuito de: diminuir o isolamento nesse períodos de estresse; manter a rotina de alunos e professores; garantir a continuidade do semestre letivo e o desenvolvimento dos conteúdos; pensar estratégias de permanência e diminuição da evasão dos alunos, ou seja, dar continuidade ao ensino presencial.

Já os estudantes estão em processo de adaptação e utilização das tecnologias para: aprender a aprender; organizar sua rotina de aula e estudo em seu 
ambiente familiar; administrar a falta do ambiente escolar, dos amigos, dos professores; dessa forma, adequações para uma nova netiqueta.

Com esse cenário, acreditamos que o professor tem sido o eixo norteador da mudança. A sua predisposição em aprender, em se reinventar, em buscar formas e estratégias de apresentar o processo de ensino e aprendizagem de forma atrativa, científica e acessível para os estudantes, tem permitido a continuidade do processo educacional. Por meio das práticas pedagógicas adotadas como: a combinação de estratégias de aprendizagem por meio das metodologias ativas; a combinação de meios (encontros síncronos, atividades assíncronas, reuniões em grupos, materiais digitais, etc); acolhimento psicológico; interação com e entre os professores; flexibilização dos tempos; busca-se garantir os direitos e objetivos de aprendizagem, bem como, a reorganização do calendário escolar.

É importante ressaltar que o Brasil apresenta problemas que são caracterizados como pré-modernos, modernos e pós-modernos (BOTO, 2020). A pandemia nos traz a dimensão de um problema pré-moderno, quase medieval. Ao mesmo tempo, vivemos uma dinâmica da modernidade quando pensamos nas questões de pobreza e da desigualdade social, bem como, a necessidade de superar essas distâncias sociais. Entretanto, precisamos enfrentar as questões da tecnologia, numa dimensão pós-moderna. Diante disso, verificamos que estamos vivendo tudo junto, misturado e ao mesmo tempo. Foi o que vivenciamos nas disciplinas oferecidas no segundo semestre do Mestrado Profissional em Educação Profissional e Tecnológica (ProfEPT). Este curso, segundo Machado, Urbanetz e Pinto (2019):

foi o primeiro mestrado em rede ofertado pelos Institutos Federais (IFs);

foi idealizado pelo Conselho Nacional das Instituições da Rede Federal de Educação Profissional, Científica e Tecnológica (CONIF) e coordenado nacionalmente pelo Instituto Federal do Espírito Santo (IFES);

objetiva a formação voltada à Educação Profissional e Tecnológica, aos profissionais da Rede Federal de Educação Profissional, Científica e Tecnológica (RFEPCT), tanto à produção de conhecimento, como para o desenvolvimento de produtos, por meio da realização de pesquisas que integrem os saberes inerentes ao mundo do trabalho e ao conhecimento sistematizado; 
apresenta uma estrutura curricular com 480 (quatrocentos e oitenta) horas de atividades didáticas, desenvolvido em 04 (quatro) semestres, com disciplinas obrigatórias, disciplinas eletivas e disciplinas de Orientação.

Dentre as atividades obrigatórias do ProfEPT, está a disciplina "Teorias e Práticas do Ensino e Aprendizagem (TPEA)", que é desenvolvida no segundo semestre do curso, ou seja, aconteceu no primeiro semestre de 2020. A disciplina chegou a iniciar presencialmente, e, por um período, suas atividades letivas foram suspensas.

A portaria $n^{\circ} 345$ (BRASIL, 2020a), de 19 de março de 2020, que alterou a Portaria MEC n 343 (BRASIL, 2020b), de 17 de março de 2020, autorizou, em caráter excepcional, a substituição das disciplinas presenciais, em andamento, por aulas que utilizem meios e tecnologias de informação e comunicação, por instituição de educação superior integrante do sistema federal de ensino.

Considerando a autonomia didático-administrativa do Programa de PósGraduação em Educação Profissional e Tecnológica - ProfEPT, em reunião de seu órgão deliberativo, o Comitê Gestor, determinou-se a continuidade das atividades acadêmicas no semestre 2020-1 de forma não presencial e a partir do uso de meios e tecnologias de informação e comunicação, de modo a garantir a manutenção das Disciplinas Obrigatórias e Eletivas por meio das ferramentas: Web Conferência RNP, Google Hangouts, Plataforma Moodle, entre outras.

As aulas foram suspensas sem previsão de retorno e o ponto chave discutido era a pensar a melhor forma de reorganizar as atividades educacionais com vistas na minimização dos impactos das medidas de isolamento social, na aprendizagem dos estudantes. O ProfEPT é ofertado desde 2017 e está na sua terceira turma. As duas primeiras ofertas foram realizadas de forma $100 \%$ presencial e a terceira turma, por meio de Atividades Pedagógicas Não Presenciais (APNPs) mediadas ou não por tecnologias digitais de informação e comunicação. Diante disso, este artigo objetiva analisar as contribuições da TPEA no processo de formação de mestrandos da EPT em cenários de pandemia.

2 As APNPs da disciplina Teorias e Práticas do Ensino e Aprendizagem no ProfEPT 
Mesmo reconhecendo as dificuldades e limites do processo em estamos vivendo, as Instituições Associadas ${ }^{3}$ (IAs) tiveram que organizar suas propostas de ensino e aprendizagem para a disciplina TPEA por meio de Atividades Pedagógicas Não Presenciais (APNPs), que são aquelas a serem realizadas pela instituição de ensino com os estudantes, quando não for possível a presença física destes no ambiente escola (BRASIL, 2020c).

Ressalta-se que as APNPs se diferem das ações da Educação a Distância $(E a D)$, que utilizam estratégias pedagógicas com a junção de recursos tecnológicos, sejam eles, impressos, audiovisuais e/ou colaborativos (MACHADO; MATOS, 2015), para apoiar ações didáticas neste momento emergencial. Com isso, diferenciam-se da EaD, modalidade que possui normas, metodologias e conceitos específicos de implementação. Mesmo com características diferentes entre APNPs e EaD, observase no estudo de Paschoalino, Ramalho e Queiroz (2020), reflexões em relação ao desafio docente e a reinvenção dos cursos de EaD referente aos processos avaliativos, diante do período de pandemia pela COVID 19.

Nesse contexto desafiador e até então desconhecido, foram instaurados os encaminhamentos necessários para o desenvolvimento das APNPs/TPEA. O primeiro deles, foi a definição da gestão e da organização do espaço pedagógico virtual, com foco nas estratégicas que possibilitassem a formação integral e significativa do mestrando, enquanto o segundo trata dos fundamentos das práticas educativas e do desenvolvimento curricular a partir do contexto educacional, do currículo, do professor, do aprendiz e da sua aprendizagem.

O objetivo principal da organização didática de uma disciplina, de acordo com Veiga (2008), é possibilitar um trabalho mais significativo e colaborativo, consequentemente, mais comprometido com a qualidade das atividades previstas. A proposta para o desenvolvimento da disciplina e, por conseguinte, da aula, é marcado para Silva (2011), pela aprendizagem de todos os seus protagonistas e esse é, para Freire (1996), um momento complexo de estudo. O próprio hábito de estudo se desenvolve. O material de estudo se transforma. A relação entre professor e aluno é

\footnotetext{
${ }^{3}$ Instituições que integram a Rede Nacional do ProfEPT e, por meio de suas Coordenações Acadêmicas Locais, com base no regulamento, são responsáveis pela gestão local do ProfEPT.
} 
recriada. Portanto, o planejamento se reveste de um caráter político e pedagógico e, de acordo com Silva (2011), ao expressar um compromisso com a formação dos sujeitos, por meio da seleção e da organização dos objetivos, conteúdos, estratégias metodológicas e avaliativas, podem contribuir para rever os processos de ensino pautados pela transmissão-recepção, com o intuito de transformar as realidades: pessoal, educacional e social.

No caso da disciplina em questão, apresentava a carga horária de 60 (sessenta) horas e sua organização didática foi estabelecida por meio de 15 encontros, de quatro horas/aula cada. A metodologia proposta foi pautada na articulação teórico-prática, com a proposição de conteúdos e diferentes atividades. Para esta estruturação, concordamos com Novak (apud MOREIRA, 2011) ao considerar que: i) a educação é um conjunto de experiências (cognitivas, afetivas e psicomotoras) que contribuem para o engrandecimento do indivíduo para lidar com a vida diária; ii) qualquer evento educativo é uma ação para trocar significados (pensar) e sentimentos entre o aprendiz e o professor; iii) que qualquer fenômeno educativo, envolve direta ou indiretamente, "cinco lugares comuns": o aprendiz, o professor, o currículo, o contexto e a avaliação. Para que o episódio de ensino seja efetivamente educativo é necessária uma relação harmoniosa entre essas partes, como resultado desta relação, acontece a aprendizagem significativa e, para tanto, arrola-se uma reflexão sobre o contexto educacional no que se refere ao professor, o aluno, a metodologia e a avaliação.

Escolher objetivos que atendam às necessidades de aprendizagem é sempre um desafio, pois segundo Silva (2011), eles são os anunciadores explícitos do que se espera do professor e dos alunos no processo didático. Na proposta pedagógica, a disciplina Teorias e Práticas no Ensino e Aprendizagem é ofertada no segundo semestre do curso e com os objetivos de: i) profundar o estado do conhecimento das concepções, das teorias da educação e da formação de professores articulada à prática docente, com foco na problematização levantada nos projetos de pesquisa e nos produtos educacionais dos mestrandos; e ii) provocar a reflexão e a análise crítica para a produção do conhecimento na área da EPT, de modo a expressar os fundamentos epistemológicos e paradigmáticos, que envolvem 
a Teoria e a Prática do Ensino e Aprendizagem na Educação, com vista à construção de uma prática pedagógica inovadora.

A partir desses objetivos foram estabelecidas as etapas para 0 desenvolvimento do conteúdo, numa complexidade crescente, e considerando os conhecimentos prévios dos alunos sobre os conteúdos. Pois, ao partir dos conhecimentos prévios dos alunos, Silva (2011) afirma que o professor torna possível na aula a construção de novos saberes, ressignificando os saberes científicos e os do senso comum. Nesta perspectiva, adotou-se como princípios articulados ao processo da aula, baseado em Silva (2011), que o conhecimento é construído por meio do diálogo, que o pensar crítico alicerça a experiência dialógica e que a relação pedagógica entre professor e aluno viabiliza o diálogo.

O processo de formação continuada foi desenvolvido tendo, como "pano de fundo", a investigação dos possíveis caminhos para uma prática pedagógica crítica, reflexiva e transformadora.

Para tanto, foram propostas discussões teóricas, realizadas a partir das leituras individuais e coletivas, da bibliografia básica e o levantamento dos pressupostos teóricos e práticos sobre: a) paradigmas do conhecimento, teorias educacionais e teorias do ensino; b) objetivos da educação e mundo contemporâneo; c) a pedagogia crítica e o embate teórico com as teorias educacionais contemporâneas; d) teorias pedagógicas, processos formativos e suas implicações nas práticas educativas, na formação de professores e na gestão organizacional de processos educativos na educação profissional e tecnológica.

A partir deste referencial teórico, semanalmente os mestrandos realizam atividades avaliativas diversificadas. Após as discussões das temáticas propostas em sala de aula, realizavam produções individuais e coletivas e disponibilizavam-nas para todo o grupo numa pasta individual e específica do Ambiente Virtual de Aprendizagem, no Google Classroom.

Conforme desenvolviam suas produções, os mestrandos elaboraram e organizaram continuamente seu Portfólio Digital. As atividades avaliativas foram estruturadas pedagogicamente para entrega semanal, entretanto, os estudantes puderam optar se essa entrega ocorreria durante o processo ou no final dele. 
A disciplina foi planejada no início de 2020 para aulas presenciais, chegamos a ter um encontro presencial, porém, devido a pandemia, o período de isolamento social iniciou na semana seguinte. Após um período de suspensão das atividades pedagógicas, em abril de 2020 iniciamos com os encontros virtuais e as APNPs.

Para o desenvolvimento das ações, utilizamos como estratégias pedagógicas: fórum; fórum invertido, onde cada mestrando elaborou uma pergunta e posteriormente escolheu uma pergunta de outro colega para responder; momentos de trabalho em grupo via WhatsApp e reunião via videoconferência de toda a turma para o compartilhamento dos estudos; elaboração de mapa conceitual voltado para uma das temáticas; elaboração de um podcast sobre um dos textos-base; escolha de um dos podcasts elaborados pelos colegas para a construção de um texto sobre os pontos relevantes apresentados pelo autor; participação em duplas/trio no Seminário sobre Teorias de Aprendizagem da disciplina; construção coletiva de um quadro sinóptico sobre as Teorias de Aprendizagem apresentadas no Seminário; construção de um texto coletivo, por grupos de trabalho, com pontos convergentes e divergentes apresentados pelos autores estudados e, para o fechamento da disciplina, construção de um artigo científico, individual ou em dupla, com a utilização de referência(s) trabalhada(s) na disciplina.

Conforme já citado, a disciplina é/foi composta por 15 encontros, sendo que o $1^{\circ}$ encontro aconteceu presencialmente e os demais encontros foram por videoconferência, semanalmente, com a duração de aproximadamente 3 horas cada encontro.

Considerando a faixa etária dos mestrandos, entre 24 a 54 anos, sendo a relação educacional do adulto baseada na interação entre professor/facilitador e o aprendiz, a aprendizagem se pautou na reciprocidade, num ambiente de liberdade, que propiciou a troca de experiências. A prática educacional do adulto baseia-se na reflexão e ação, logo, as atividades desenvolvidas podem conter nas suas estratégias momentos para a discussão do assunto em pauta e para a colocação em prática das conclusões obtidas.

\section{Procedimentos metodológicos}


Este artigo analisa as contribuições de uma experiência vivenciada com o Portfólio Digital durante uma pesquisa de abordagem qualitativa, do tipo exploratória, realizada durante uma formação continuada, nos encontros da disciplina "Teorias e Práticas do Ensino e Aprendizagem", do Mestrado em Educação Profissional e Tecnológica em Rede, de uma Instituição de Educação Profissional e Tecnológica de Curitiba, ministrada no $1^{\circ}$ semestre de 2020.

Ao término da disciplina e para sua avaliação, optou-se pela aplicação de um questionário formativo, com o "propósito de obter informações sobre conhecimentos, crenças, sentimentos, valores, interesses, expectativas, aspirações, temores, comportamento presente ou passado, etc" (GIL, 2008, p. 121).

Esse questionário formativo foi: i) organizado pelas docentes da disciplina; ii) elaborado com perguntas sobre o programa e o desenvolvimento da disciplina pelas professoras: 12 (doze) perguntas fechadas e 01 (uma) questão aberta: "Quais as suas Sugestões e/ou considerações sobre o Programa e o Desenvolvimento da disciplina?" e sobre a Autoavaliação: 03 (três) perguntas fechadas e 01 (uma) questão aberta: "Quais as suas considerações sobre seu processo de construção do conhecimento participando desta disciplina?"; e iii) aplicado de forma online ao final da disciplina. Destes, 23 (vinte e três) mestrandos responderam ao questionário, dos quais, 15 são do sexo feminino e 08 do sexo masculino, atuando em diferentes áreas do conhecimento: Administração, Arquitetura, Biblioteconomia, Composição e Regência, Desenho Industrial, Design Gráfico, Direito, Economia, Educação Física, Filosofia, Física, Geografia, Gestão Pública, História, Letras, Música, Pedagogia, Psicologia, Serviço Social e Sociologia.

Para verificar as respostas dos 23 questionários, foi realizada a Análise do Conteúdo (AC), que é definida por Bardin (2011) como o conjunto de instrumentos metodológicos aplicados a conteúdos diversificados e, neste estudo, seguimos as etapas: coleta de dados, preparação dos dados, codificação, categorização e a análise de conteúdo.

A coleta de dados foi realizada com a aplicação dos questionários. $\mathrm{Na}$ preparação dos dados, foi realizada a leitura "flutuante" de todo o material coletado e selecionadas as respostas que apresentaram significativa contribuição para 
responder ao objetivo desta pesquisa. No processo de codificação foi realizada a criação de códigos para a posterior categorização. As categorias de análise desta pesquisa foram as respostas da pergunta aberta e, para que fosse identificada sua incidência, nesta pesquisa cada participante recebeu um código de identificação. A categorização foi realizada, isolando os elementos e separando-os conforme suas mensagens, por meio da análise categorial, que consistiu no agrupamento progressivo das categorias: (iniciais $\rightarrow$ finais) em unidades de registro (palavras, frases, parágrafos) comparáveis e com o mesmo conteúdo semântico. Essa categorização partiu do todo (categorias iniciais) para o particular (categorias finais).

Para realizar a análise de conteúdo e direcionar o processo de escrita, a discussão e análise das informações coletadas, realizamos: i) a leitura das respostas de todos os mestrandos - já agrupadas pelo seu sentido semântico; ii) a reflexão sobre cada categoria de análise e; iii) a busca por sustentação ou aporte teórico, para que as interpretações fossem subsidiadas e que fundamentassem a análise das percepções dos mestrandos quanto às contribuições da TPEA como espaço de Formação para a EPT.

\section{Contribuições da disciplina TPEA: análise e discussão dos dados}

Os procedimentos de organização dos questionários possibilitaram a identificação de duas categorias iniciais quanto as contribuições da TPEA como espaço de Formação para a EPT: i) na proposta das Atividades Pedagógicas Não Presenciais (APNPs) e ii) na aprendizagem do mestrando. As categorias iniciais se configuram como as primeiras impressões acerca da realidade estudada. Para definilas, realizou-se a separação de todo o corpus da análise, agrupando as respostas dos respondentes a partir da indagação intencional no questionário.

Da mesma forma, à medida que se entrelaçavam as cadeias de significações aglutinadas por similaridade de conteúdo e por meio da separação progressiva dessas categorias iniciais, foram sendo conduzidas às categorias finais. Do refinamento das duas categorias iniciais, emergiram 08 categorias finais e se constituíram como indicadores das contribuições da TPEA como espaço de Formação para a EPT. As categorias finais representam a síntese do aparato das significações, identificadas no decorrer da análise dos dados do estudo e é por meio delas que 
promovemos interpretações, inferimos resultados e respondemos ao objetivo proposto para esta pesquisa.

Ao final do processo de análise, percepções dos respondentes quanto a proposta pedagógica, indicam que as categorias finais que apresentaram maior incidência foram:

\section{Promoveu a autonomia}

Segundo 13 estudantes, houve o aprimoramento do conhecimento produzido favorecendo o desenvolvimento da autonomia. Este princípio está diretamente ligado a escolha do mestrando, a forma de organizar e apresentar sua produção desenvolvida e na busca de formas diferentes de aprender. Foram incentivados por meio de procedimentos em que os mestrandos organizaram seus próprios estudos, buscando fontes de informação e conhecimento, e construindo um saber ligado aos seus próprios objetivos de aprendizagem. Estabeleceu-se por meio de uma prática mediacional dialógica, num exercício de abertura ao mestrando, respeitando suas diferenças e os tempos de cada um, num movimento de liberdade e responsabilidade para a escolha dos caminhos no processo de construção do seu conhecimento.

\section{Estimulou a Pesquisa}

De acordo com 19 estudantes, o estímulo a pesquisa se configurou como condição fundamental para a conquista da autonomia intelectual do mestrando. Para tanto, foram estimulados a aprender a pesquisar e a dominar diferentes formas de acesso às informações, além de desenvolver sua capacidade crítica de avaliar, de reunir e de organizar informações muito mais relevantes.

\section{Incentivou à colaboração}

De acordo com 09 estudantes, a organização das APNPs estimulou a colaboração e favoreceu a parceria entre professores e entre estudantes, minimizando as ações e atitudes verticalizadas e centralizadoras. A colaboração foi defendida pelos professores como uma metodologia com potencial para promover uma aprendizagem mais ativa por meio do estímulo: i) ao pensamento crítico; ii) ao 
desenvolvimento de capacidades de interação; iii) à negociação de informações e à resolução de problemas; e iv) ao desenvolvimento da capacidade de autorregulação do processo de aprendizagem e ensino (TORRES; IRALA, 2014). Essa forma de aprender e ensinar tornou os estudantes mais responsáveis por sua aprendizagem, levando-os a construir conhecimentos de forma mais significativa. O desenvolvimento de uma ação colaborativa implica em planejamento, desenvolvimento de ações comuns, o estabelecimento de conexões, reflexão sobre o processo juntos com os pares. Parte da compreensão de que cada membro do grupo é responsável pela sua aprendizagem, corresponsável pelo desenvolvimento do grupo e se tornam ao mesmo tempo, autor e coautor de produções coletivas.

\section{Promoveu a interação}

Para 13 estudantes a proposta pedagógica promoveu a interação e, assim, caracterizou-se como um dos fatores mais importantes para o sucesso do processo de produção. A comunicação, a interação e a interatividade foram elementos basilares para que o processo de aprendizagem e ensino acontecesse. A interação permitiu manter uma relação de comunicação entre mestrandos e professores, sendo uma estratégia em que a atitude de pesquisa sistêmica foi estimulada e extremamente útil na compreensão do processo de ensino e aprendizagem, por meio de suas dimensões cognitivas, afetivas e de ação.

Continuando o processo de análise, as percepções dos respondentes quanto a aprendizagem dos mestrandos, indicam que as categorias finais que apresentaram maior incidência foram:

\section{Promoveu a reflexão crítica}

De acordo com 10 estudantes, o processo de aprendizagem promoveu a reflexão crítica sobre as suas produções. Foi por meio da reflexão crítica durante as discussões e o processo de produção que os estudantes analisaram suas produções, elaboraram argumentos para sustentar suas próprias opiniões por meio da atenção, categorização, seleção, do julgamento e optaram em refazê-las sempre que julgaram necessário. A formação de julgamento da situação presente, para Dewey (1997), desenvolve-se quando o indivíduo pensa e reflete sobre as experiências passadas e 
consegue identificar similaridades entre as experiências passadas e as presentes. A partir desse momento, o estudante assume a responsabilidade na planificação, na organização e na avaliação da sua aprendizagem.

\section{Promoveu a construção coletiva}

Para 08 mestrandos a proposta pedagógica promoveu a construção coletiva, entendendo-a como um processo negociado de um grupo por meio da convergência de ideias e significados, que são interpretados em função de suas experiências, culturas e histórias de vida em função de um propósito comum. Nesse sentido, a organização dos materiais, as situações de aprendizagem e ensino requereu ações integradas, compartilhadas e em tempo contínuo. O compartilhamento dessas ações e de aprendizagem, como processo de construção coletiva, foi o diferencial desta proposta. Para tanto, foi necessário compartilhar experiências individuais e coletivas e se reconhecer nelas. Desde o início e, ao longo do curso, o mestrando foi motivado a indagar a si mesmo, a questionar a sua realidade, seus problemas e suas experiências exitosas, bem como, a transformá-los em perguntas de pesquisa. A construção coletiva e as ações pedagógicas se desenvolveram no AVA e a construção do conhecimento ocorreu por meio dos diálogos, das interações, das trocas e das partilhas de experiências. Os mestrandos enfatizaram diferentes aprendizagens nos debates propiciados, discorreram que as experiências relatadas, as argumentações com base nos diversos textos e autores estudados, com a revisitação de conceitos e os depoimentos em distintas perspectivas, contribuíram para uma construção de conhecimento coletiva e maior compreensão das problemáticas que perpassam a realidade escolar. Esse exercício de tomada de conhecimento, da reflexividade, fundamenta-se em Zeichner (2008).

\section{Favoreceu o aprofundamento teórico}

Numa ação gradual de reflexão crítica, autonomia e pesquisa, segundo 11 estudantes, foram conduzidos a avaliar permanentemente seu progresso, favorecendo o aprofundamento teórico. Os mestrandos apontaram a densidade de estudos, as contribuições para a compreensão da temática educação, inclusive em relação a EPT e que estão em processo de internalização dos conteúdos abordados. 
Por ser uma disciplina que trabalha com o enfoque: na escola, no professor, no aluno, na metodologia e na avaliação, são leituras com temáticas que permeiam a realidade dos mestrandos em seus percursos como estudantes e/ou mesmo em sua prática pedagógica, considerando os que já são professores. Porém, apesar das temáticas estarem presentes, o estudo com este teor mais denso exige dos mesmos maior abstração e a internalização ocorre em diferentes níveis, dependendo do amadurecimento pessoal em relação a leituras e/ou vivências pedagógicas. Dessa forma, alguns sinalizaram o aprofundamento teórico das temáticas abordadas como um processo intrínseco e contínuo para os profissionais da educação.

\section{Desenvolveu a autoria e coautoria}

Por último, o desencadeamento do processo pedagógico para 06 estudantes, desenvolveu a autoria e coautoria das produções durante a organização do trabalho pedagógico e na construção de um novo conhecimento, agora embasado e construído a partir de concepções particulares, experiências de vida e em que foram geradas produções científicas a partir das vivências durante o processo de ensino e aprendizagem.

Assim sendo, a experiência nos mostrou que a proposta pedagógica desenvolvida teve merecido destaque em quatro princípios básicos: i) da autonomia; ii) da pesquisa; iii) da interação; e iv) da colaboração. Por meio desses princípios promoveu-se nos mestrandos múltiplas aprendizagens: i) aprofundamento teórico; ii) a construção coletiva; iii) a reflexão crítica; e iv) a autoria e a coautoria nos envolvidos no processo. Após esta vivência, sistematizamos na Figura 1 o processo de ensino aprendizagem desenvolvido: 


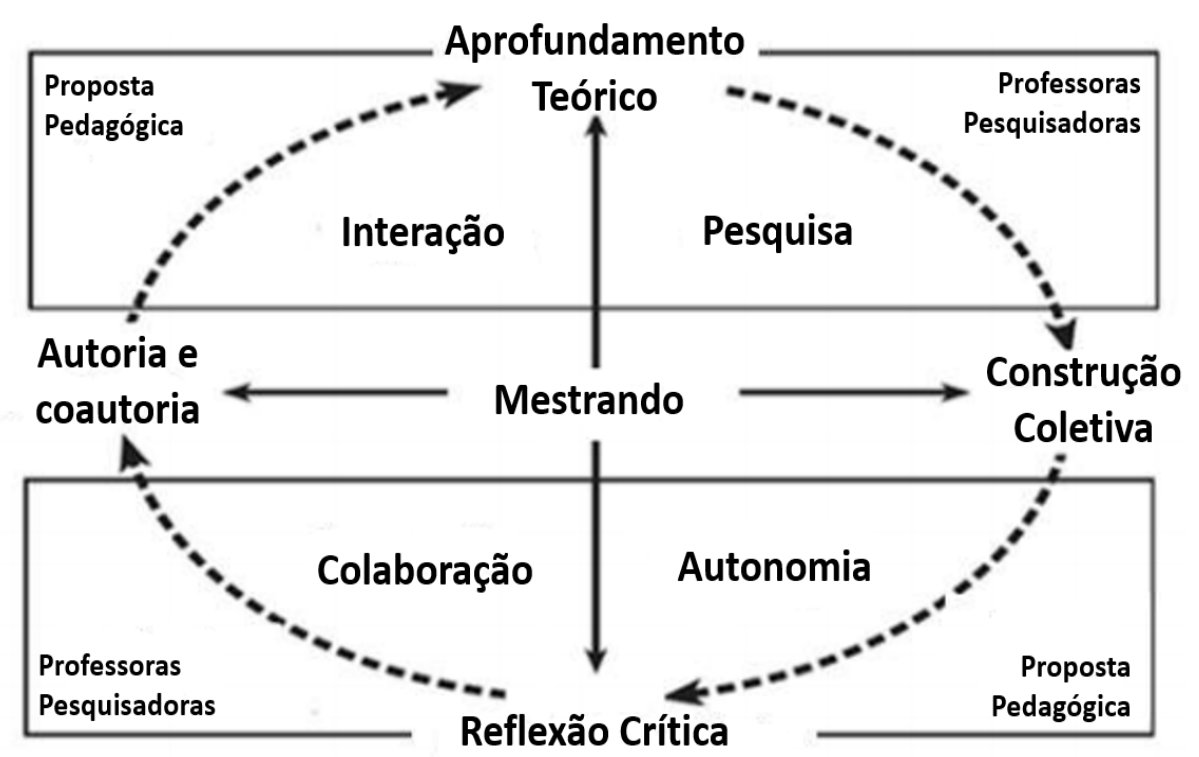

Figura 1. Práxis avaliativa por meio do Portfólio Digital

Fonte: as autoras (2020)

Um dos pontos apresentado pelos mestrandos foi a importância do papel da mediação pedagógica realizada pelas professoras da disciplina no acompanhamento do desenvolvimento de todas as atividades pedagógicas, promovendo a articulação das temáticas para garantir a integração dos temas para a produção científica final. Para os entrevistados, foi devido ao seu papel atuante que não se perdeu o fio condutor do processo do começo ao fim. O papel das professoras na mediação com os mestrandos foi complexa, justamente porque cada um tinha seus pleitos, gostariam de trabalhar com um tempo e com um nível de quantidade de exercícios, muitas vezes maiores do que as possibilidades permitiram e a experiência delas foi um aliado no "tem que dar certo" do processo. A construção desse processo pedagógico inovador demandou muito esforço e foi sendo construída ao longo do tempo, o que significou muito trabalho para as mediadoras, já que a perspectiva trabalhada na mediação com os mestrandos foi de desconstrução de um trabalho individualizado, em detrimento de uma ação de coletividade.

Contudo, apesar da maioria dos respondentes destacarem as contribuições da disciplina TPEA, alguns dos respondentes revelaram que sentiram falta de: i) explicações teóricas por parte das professoras; ii) falta de referências na área de gestão; e iii) tempo para dedicação às leituras e atividades. Dessa forma, podemos 
concluir que o conhecimento foi construído por meio da conexão de múltiplas dimensões e da ligação dos saberes em que:

- o mestrando foi caracterizado como um ser complexo, único, competente, valioso e, portanto, protagonista, motivado, autônomo, reflexivo e crítico;

- as professoras assumiram o papel de parceiras, amigas e colaboradoras, mas críticas, exigentes e comprometidas, trabalhando com a visão de totalidade do mestrando e do processo;

- a metodologia de ensino contemplou um currículo flexível, unindo teoria e prática, por meio de uma prática pedagógica crítica, reflexiva, autônoma e transformadora, em que professoras e mestrandos estabeleceram suas próprias estratégias para a construção do conhecimento mútuo;

- a avaliação estava focada na pesquisa e possibilitou ao estudante, as professoras e mestrandos utilizarem sua teoria prática (CRUZ, 2001) para a construção de um empreendimento cooperativo (BEHRENS, 2006), das atividades ao artigo científico, acolhendo contribuições de todos os envolvidos no processo;

- a mediação da aprendizagem foi constituída como princípio educacional e como uma posição humanizadora, positiva, construtiva e potencializadora no complexo mundo da relação educativa (TÉBAR, 2011).

Diante de toda a construção e do processo analítico, destacamos que a complexidade com que se estabeleceu as ações mediacionais na TPEA exigiu uma postura diferenciada das professoras frente ao processo de aprendizagem e ensino, que repercutiu na reflexão e na percepção dos mestrandos sobre a proposta pedagógica e sobre a própria aprendizagem.

\section{Considerações}

O cenário de pandemia gerou instabilidade, mas também oportunidades para aprendizado. Mesmo com o planejamento todo construído para encontros presenciais, tivemos que realizar diferentes adaptações para que a disciplina acontecesse de maneira virtual. Foram diversos estudos para ver as possibilidades de diferentes plataformas virtuais, até a escolha do Google Classroom, Após sua escolha, o estudo se referiu sobre as ferramentas disponibilizadas na plataforma, 
sobre a inserção de atividades, de manuseio, de postagens e de acesso às informações postadas, tanto pelas professoras, quanto pelos mestrandos.

Além do conteúdo programado, nosso objetivo, ao propormos Atividades Pedagógicas Não Presenciais em cumprimento as diretrizes do ProEPT, foi trazer alguma inovação aos processos pedagógicos remotos. Houve a ampliação dos estudos referentes as estratégias pedagógicas, metodologias ativas e que elas pudessem provocar, instigar aos mestrandos possibilidades de, inclusive, replicar as práticas desenvolvidas.

Algumas estratégias pedagógicas são/foram mais comuns, como: construção de texto individual e coletivo, fóruns, elaboração de mapas mentais, quadros sinópticos e artigo. Porém, estratégias pedagógicas como: o encontro para a realização do trabalho em grupo via WhatsApp, criação de podcasts, videoconferências realmente interativas, fóruns invertidos e intervenções sob a construção do colega, ou seja, a estratégia de registrar suas percepções com base no material postado pelo colega, sobre um dos conteúdos tratados, foram anunciadas como novidade por alguns mestrandos.

Nas discussões foi possível observar que o ensino e a aprendizagem podem acolher um processo dinâmico, construtivo, reflexivo, que subsidiam a participação ativa e autônoma dos participantes produzindo o conhecimento, mesmo em tempos de distanciamento social.

Os mestrandos e as professoras perceberam que é urgente a priorização da aprendizagem, voltar a atenção para seus estudantes e para suas necessidades e buscar avanços nos novos paradigmas, que satisfaçam essas demandas. Para que isso aconteça, deve-se deslocar o foco da "reprodução" para a "produção" do conhecimento.

A experiência aqui realizada agregou atividades individuais e coletivas propostas num processo que refletiu o comprometimento e envolvimento dos mestrandos mediados pelas professoras. As produções elaboradas apresentaram resultados significativos de aprofundamento nos temas investigados e promoveram a oportunidade para o desenvolvimento de uma prática inovadora, pautado na reflexão crítica, na pesquisa, na individualidade do processo, no fomento da autonomia, no 
estabelecimento de colaboração e interação entre os mestrandos e as professoras, e no desenvolvimento da autoavaliação, da autoria e coautoria do ensinar e aprender entre todos os envolvidos. Nesta perspectiva, este estudo apontou que:

- A diversidade de atividades para compor o processo pedagógico proposto para esta disciplina favoreceu o processo formativo, pois contemplou distintos estilos de aprendizagem dos mestrandos e com isso favoreceu o processo de produção de conhecimento;

- A escolha do Portfólio Digital como estratégia pedagógica foi assertiva, pois os mestrandos realizavam suas atividades semanalmente, num movimento progressivo de aprendizagem;

- A experiência das professoras pesquisadoras contribuiu para a condução do processo de aprendizagem, na identificação dos avanços e dificuldades dos mestrandos, auxiliando-os ao longo do processo.

Um processo de formação pautado numa abordagem inovadora é extremamente trabalhoso, requer muita dedicação, compromisso e paciência. Cada aluno aprende de maneira diferente, tem um ritmo de aprendizagem, interesses e motivações intrínsecas e a organização de um processo de aprendizagem colaborativa deve promover a reflexão, discussão e a construção de um novo conhecimento, agora embasado e construído a partir de concepções particulares, experiências de vida e de um contexto histórico.

Ou seja, todo processo de avaliação deve fornecer oportunidades para a troca de experiências, de saberes, ou seja, a possibilidade para construir e fomentar práticas inovadoras e, ao influenciar positivamente o ensino, a aprendizagem e a avaliação podem criar um novo conceito de sala de aula: um lugar onde o aprendizado é construído de acordo com o ritmo individual de cada estudante, incluindo a valorização do pensamento reflexivo, experiência, intuição, o conhecimento de cada indivíduo e a crença de que as dificuldades podem ser superadas.

Embora continuemos em uma fase inicial de desenvolvimento da implementação das APNPs em contextos educacionais, acreditamos que elas podem se tornar uma estratégia interessante, que promovam a reflexão sobre as práticas dos professores e tenham grandes potencialidades em relação à inovação curricular. 
A construção desta proposta permitiu o desenvolvimento de ambientes de aprendizagem mais participativos, bem como, favoreceram a conscientização de cada estudante sobre o que e como está aprendendo.

Apesar da construção do artigo acadêmico ser uma atividade comum em programas de pós-graduação, percebemos a resistência de parte dos mestrandos para essa atividade, por motivos que envolvem: iniciação na escrita acadêmica, "medo" do desconhecido; densidade de trabalhos da disciplina e demais disciplinas no mesmo período.

Alguns mestrandos optaram em realizar a escrita do artigo em dupla, com a participação de seus orientadores no texto e o processo se tornou outra aprendizagem colaborativa. E, ainda, alguns chegaram a submeter para revistas antes mesmo da finalização da disciplina e tiveram a aprovação dos artigos em periódicos, cumprindo com o objetivo estimulado para a respectiva atividade - desenvolvimento da escrita acadêmica formal e compartilhamento dos estudos desenvolvidos com o meio acadêmico, para além da comunidade em que estamos inseridos.

O professor desempenha um papel de vital importância na gestão do processo e no suporte efetivo à aprendizagem individual. Embora eles possam ser efetivamente construídos com os meios tradicionais, a possibilidade de utilizar meios digitais traz um enorme potencial se convenientemente integrado e utilizado no contexto educacional. No entanto, relaciona-se ao domínio dessas ferramentas para a utilização, especificamente no que diz respeito à sua escolha, no conhecimento das potencialidades de cada recurso digital, adequação à proposta e aos seus objetivos metodológicos.

\section{Referências}

BARDIN, Laurence. Análise de Conteúdo. São Paulo: Edições 70, 2011.

BEHRENS, Marilda Aparecida. Paradigmas da Complexidade: Metodologia de Projetos, Contratos Didáticos e Portfólios. Petrópolis, RJ: Vozes, 2006.

BOTO, Carlota. Educação em tempos de pandemia. Youtube, 07 de maio de 2020. Disponível em https://www.youtube.com/watch?v=NvWRoA09C4Q Aceso em 20 jul. 2020. 
BRASIL. Portaria $n^{\circ} 345$, que altera a Portaria $n^{\circ} 343$, sobre a substituição das aulas presenciais por aulas em meios digitais enquanto durar a situação de pandemia do Novo Coronavírus - COVID-19. Ministério da Educação/Gabinete do ministro. Disponível

em: $<$ http://pesquisa.in.gov.br/imprensa/jsp/visualiza/index.jsp?jornal=603\&pagina=1\&dat $a=19 / 03 / 2020$ \&totalArquivos=1>. Acesso em: 20 mar. 2020a.

BRASIL. Portaria $n^{\circ} 343$, que dispõe sobre a substituição das aulas presenciais por aulas em meios digitais enquanto durar a situação de pandemia do Novo Coronavírus - COVID-19. Ministério da Educação/Gabinete do ministro. Disponível em: <http://www.in.gov.br/en/web/dou/-/portaria-n-343-de-17-de-marco-de-2020248564376 >. Acesso em: 20 mar. 2020b.

BRASIL. Parecer do Conselho Nacional de Educação Câmara de Educação Básica $n^{\circ} 5$ de 28 de abril de 2020, que trata da Reorganização do Calendário Escolar e da possibilidade de cômputo de atividades não presenciais para fins de cumprimento da carga horária mínima anual, em razão da Pandemia da COVID-19. Diário Oficial da União, Brasília, 01 de junho de 2020, Seção 1, Pág. 32 Disponível em: <http://portal.mec.gov.br/index.php?option=com_docman\&view=download\&alias=14 5011-pcp005-20\&category_slug=marco-2020-pdf\&ltemid=30192>. Acesso em: 01 jul. 2020c.

CRUZ, Dulce Márcia. O Professor Midiático: a formação docente para a educação a distância no ambiente virtual da videoconferência. 2001. Tese (Doutorado em Engenharia de Produção) - Universidade Federal de Santa Catarina, Florianópolis, 2001.

DEWEY, John. Como pensamos. São Paulo: Cia Editora Nacional, 1997.

FREIRE, Paulo. Pedagogia da autonomia: saberes necessários à prática educativa. 13. ed. Rio de Janeiro: Paz e Terra, 1996.

GIL, Antônio Carlos. Métodos e técnicas de pesquisa social. São Paulo: Atlas, 2008.

MACHADO, Lucília Regina de Souza. O desafio da formação dos professores para a EPT e PROEJA. Revista Educação \& Sociedade: Campinas, v. 32, n. 116, p. 689704, jul.-set. 2011.

MACHADO, Mércia Freire Rocha Cordeiro. MATOS, Elizete Lúcia Moreira. O planejamento e uso dos recursos didáticos tecnológicos no apoio às aulas expositivas. In: FERREIRA, Jacques de Lima. (Org.). Formação de Professores: Teoria e Prática Pedagógica. Petrópolis, RJ: Vozes, 2014. p. 148-170. 
MACHADO, Mércia Freire Rocha Cordeiro; URBANETZ, Sandra Terezinha; PINTO, Leandro Rafael. ProfEPT no IFPR: cenário atual, desafios e perspectivas. Revista Debates em Educação: Universidade Federal de Alagoas, v. 11, n. 25, 2019.

MOREIRA, Marco Antônio. Teorias de Aprendizagem. 2ed. São Paulo: EPU, 2011.

PASCHOALINO, Jussara Bueno de Queiroz; RAMALHO, Maria Lúcia; QUEIROZ, Virgína Coeli Bueno de. Trabalho docente: o desafio de reinventar a avaliação em tempos de pandemia. Revista Labor. V.1, n. 23, p. 113-130, 2020.

SILVA, Edileuza Fernandes da. Nove aulas inovadoras na universidade. Campinas (SP): Papirus, 2011.

TÉBAR, Lorenzo. O perfil do professor mediador: pedagogia da mediação. Tradução: Priscila Pereira Mota. São Paulo: Senac, 2011.

TORRES, Patrícia Lupion; IRALA, Esrom. Aprendizagem Colaborativa: teoria e prática. In: TORRES, Patrícia Lupion (Org.). Complexidade: redes e conexões na produção do conhecimento. Curitiba: SENAR - PR, 2014, p. 61-94

VEIGA, IIma Passos Alencastro. Organização didática da aula: um projeto colaborativo de ação imediata. In: _ (Org.). Aula: gênese, dimensões, princípios e práticas. Campinas: Papirus, 2008a. p. 267-298.

ZEICHNER, Kenneth. Uma análise crítica sobre a "reflexão" como um conceito estruturante na formação docente. In: Educação e Sociedade. v. 29, n.103, 2008.

MEMORANDO CIRCULAR ProfEPT No 04/2020. Assunto: Deliberações do Comitê Gestor acerca do Calendário Acadêmico ProfEPT 2020-1. Em: 31 mar. 2020.

\section{Cristine Roberta Piasseta Xavier}

Curitiba, PR, Brasil

Doutora em Educação pela Pontifícia Universidade Católica do Paraná (2018). Atualmente professora do Ensino de Arte do Instituto Federal do Paraná (IFPR) Campus Curitiba, Professora permanente do Programa de Pós-Graduação em Educação Profissional e Tecnológica (ProfPET), Professora do Curso de Licenciatura em Pedagogia do IFPR Campus Curitiba e do Curso de Especialização em Educação Musical para a Educação Básica.

Email: cristine.xavier@ifpr.edu.br

Link do Lattes: http://lattes.cnpq.br/8091070374386565 


\section{Mércia Freire Rocha Cordeiro Machado}

Curitiba, PR, Brasil

Doutorado em Educação (2016) pela Pontifícia Universidade Católica do Paraná (. Atualmente é professora do Instituto Federal do Paraná e pesquisadora da Pontifícia Universidade Católica do Paraná.

Email: mercia.machado@ifpr.edu.br

Link do Lattes: http://lattes.cnpq.br/4605074118629771

Recebimento: $26 / 07 / 2020$

Aprovação: 16/09/2020

\section{Q.Code}

\section{Editores-Responsáveis}

Dr. Enéas de Araújo Arrais Neto, Universidade Federal do Ceará, UFC, Ceará, Brasil

Dr. Sebastien Pesce, Universidade de Orléans, França 